\title{
Métodos sencillos en obtención de biogás rural y su conversión en electricidad
}

\author{
Simple methods for obtaining rural biogas and its conversion into electricity
}

Ernesto Ponce ${ }^{1}$

\section{RESUMEN}

\begin{abstract}
Actualmente hay variados caminos para obtener biogás rural: desde el empleo de desechos orgánicos y pequeñas plantas para uso de familias campesinas hasta medianos y grandes sistemas. Estos últimos se utilizan para generar energía eléctrica a partir de criaderos de animales o volúmenes mayores de desechos agrícolas. En este trabajo se describen los actuales métodos más simples en uso, sus aplicaciones y restricciones. Se buscó la información en fuentes europeas, americanas, incluyendo a EE.UU. La difusión de estas técnicas permitiría renovar parcialmente las fuentes energéticas convencionales. Estas provienen de hidrocarburos, que son caros, contaminantes y que producen un efecto invernadero en la atmósfera. De producciones medianas y grandes, al contabilizar el gas consumido pueden obtenerse "Bonos de carbono". Como resultados se entregan costos aproximados de inversión, en función de la generación de gas producida.
\end{abstract}

Palabras clave: biogás, energías renovables, metano, fertilizante.

\begin{abstract}
Currently there are several ways for get rural biogas, from the use of organic waste and small plants for use by farm families to medium and large systems. The latter are used to generate electricity from breeding farms or larger volumes of agricultural waste. This paper describes the simplest methods in current use, its applications and restrictions. The information was sought in European, American sources including the United States. The spread of these techniques allow partial renewal conventional energy sources. These come from hydrocarbons, are expensive, polluting and producing a greenhouse effect in the atmosphere. From medium and large productions "carbon bonds" can be obtained, in accounting for the gas consumed. As results delivered approximate investment costs, depending on the generation of gas produced.
\end{abstract}

Key words: biogas, renewable energy, methane, fertilizer.

\section{Introducción}

El biogás proviene de una generación anaeróbica de metano, anhídrido carbónico, ácido sulfídrico y siloxanos, a partir de la descomposición de desechos orgánicos. Aproximadamente está compuesto de metano $\left(\mathrm{CH}_{4}\right) 60 \%$, anhídrido carbónico $\left(\mathrm{CO}_{2}\right)$ $35 \%$, de vapor de agua $4 \%, \mathrm{H}_{2} \mathrm{~S} 1 \%$ y trazas de otros hidrocarburos (Denker, 1966 y Pascual, 2011)). Para su correcto uso deben ser eliminados: el $\mathrm{CO}_{2}$ por no ser combustible y de carácter tóxico, así como el $\mathrm{H}_{2} \mathrm{~S}$, que resulta corrosivo para los metales y tóxico para los humanos. Por lo dicho, es importante purificar el biogás, tanto por la salud de las personas como por la eficiencia del generador.
El metano así obtenido es un combustible, es barato y no contaminante.

La capacidad calorífica del metano es de $9,97 \mathrm{~kW} / \mathrm{m}^{3}$, que es una cifra a considerar. Para purificación de gas en instalaciones de uso campesino, no es necesario usar equipos caros ni sofisticados; sin embargo, en instalaciones industriales debe emplearse purificadores acorde al volumen de producción.

A nivel industrial se puede utilizar en calderas, para generar calor en calefactores, como combustible para vehículos, en motores conectados a generadores para producir electricidad, entre otros.

Un desecho importante es el lodo ya digerido, como líquido o sólido que resulta una vez finalizado

1 Escuela Universitaria de Ingeniería Mecánica. 18 de Septiembre 2222. UTA. Arica. eponce@uta.cl

* Autor para correspondencia: eponce@uta.cl

Fecha de Recepción: 30 Octubre, 2015.

Fecha de Aceptación: 20 Junio, 2016.

DOI: $10.4067 /$ S0718-34292016005000011 
el proceso. Es un excelente material para fertilizar la tierra porque contiene elementos como nitrógeno, fósforo y potasio. El largo proceso anaeróbico destruye parásitos intestinales, de esta manera el material efluente es mejorado biológicamente a partir de la fermentación.

El valor energético de $1 \mathrm{~m}^{3}$ de biogás con un $60 \%$ de metano equivale a 0,7 litros de gasolina o 2,4 kW-hora de electricidad o $0,6 \mathrm{~m}^{3}$ de gas natural o $1,3 \mathrm{~kg}$ de madera.

Según Varnero (2012) la productividad del biogás a partir del estiércol de 10 vacunos, genera el equivalente a 4 balones de gas licuado de 15 kilos al mes, y fertilizar $300 \mathrm{~m}^{2}$ a razón de 160 unidades de nitrógeno/ha. Este cálculo se hizo en base a un volumen diario de $100 \mathrm{~kg}$ estiércol + 100 litros de agua. El tiempo de retención fue de 200 litros x 40 días. Se determinó que el volumen del digestor (litros diarios $\mathrm{x}$ número de días) $=$ 8.000 litros.

Un efecto positivo del tratamiento anaeróbico es evitar la emisión del metano, que es uno de los gases con mayor efecto invernadero. La digestión anaeróbica disminuye la emisión de olores desagradables en criaderos de animales.

Se destaca que en nuestro país solo se utiliza el $1 \%$ de energía proveniente de biomasa, dentro de la matriz energética nacional (Ministerio de Energía, 2010).

Hay diseños muy diversos de plantas de biogás, pero básicamente se componen de: instalaciones de recepción de la biomasa; reactor donde se realiza el proceso anaeróbico; depósito para almacenar el gas y otro depósito para el material de residuo; equipos para la generación de energía eléctrica (en el caso de instalaciones mayores que las de familias campesinas).

En Alemania, donde su uso se encuentra extendido, la mayoría de las plantas generan entre 150 kW y 1 MW (Al Seadi, 2010).

\section{Materiales y Métodos}

La búsqueda de información se obtuvo de Ministerio de Energía de Chile, Redagrícola Chile 2015, Latindex, European Commission(Intelligent Energy for Europe Program); Estudio Técnico PER (Plan Energías Renovables de España); Food and Agricultural Organization of the United Nations; Fideicomiso de Riesgo Compartido, Desarrollo Rural (FIRCO) entre otros.

\section{Resultados y Discusión}

\section{Método para generar biogás para parcelas familiares}

En las aplicaciones para familias campesinas es importante que dispongan de una fuente de combustible para cocinar, calefaccionar e iluminar, descartando la necesidad de consumir y recoger leña. La eliminación del humo deja menos expuestas a las mujeres y niños a este tipo de contaminante. También se reduce la contaminación por parásitos y bacterias, al desinfectar el estiércol.

Se nombrarán algunos métodos como el modelo hindú (House, 1978 y Guardado, 2006). Funciona en base a un contenedor de gas flotante sobre el biodigestor y su objetivo principal es producir una fuente de energía. Es costoso para una sola familia campesina porque consta de un depósito cuadrado de ladrillos estucados y enlucidos interiormente ( $2 \times 2 \times 1 \mathrm{~m}$ de alto) para material orgánico crudo. Va a nivel del suelo y se conecta con el biodigestor mediante una gruesa tubería (10 cm o más). La tubería une el fondo del primer depósito con el fondo del biodigestor. Este último va enterrado, también es de albañilería, tiene forma cilíndrica de $2 \mathrm{~m}$ de diámetro y $2,5 \mathrm{~m}$ de profundidad, sobresale unos $50 \mathrm{~cm}$ del suelo. En el centro está dividido en dos por un muro separador. Este va desde el fondo hasta 1,7 m de alto, su función es separar el sector de entrada donde se produce la biodigestión y permitir el rebalse hacia el sector de salida (donde se recoge por bombeo el material ya digerido). Un tubo de salida conecta la base inferior de este sector con otro depósito sobre el suelo, también de albañilería, para después emplear la masa digerida como fertilizante. Hay un domo superior de latón o fibra de vidrio, que flota como un vaso invertido, teniendo como sello el material semilíquido del cilindro. Aquí se almacena la combinación de $\mathrm{CH}_{4}, \mathrm{CO}_{2}$ y $\mathrm{H}_{2} \mathrm{~S}$. Hay una válvula que dirige esta mezcla para ser limpiada de anhídrido carbónico y ácido sulfídrico. Esta instalación es útil cuando se instala en una aldea campesina, con un servicio comunitario.

Hay un modelo chino, que se derivó del hindú, carece de depósito de gas flotante y su objetivo es más sanitario-ambiental que generador de gas, (House, 1978). Funciona en base al desplazamiento de líquidos empujados por el biogás. Se construyen de 10 a $200 \mathrm{~m}^{3}$ de volumen. También está construido 
de albañilería. Bajo el nivel del suelo hay un sector de entrada de una pendiente de un $75 \%$. Por la parte inferior se conecta al biodigestor cilíndrico. Este cilindro tiene un domo a ras del suelo donde se colecta la mezcla de gases mediante una válvula. Por la parte inferior opuesta a la entrada, hay una salida conectada a un depósito para captar el material ya digerido y enviarlo como fertilizante.

Un modelo cubano es interesante pero su costo sube debido al empleo de albañilería (Guardado, 2006).

Un modelo más reciente consta de dos membranas de geoplástico de espesor superior a $0,3 \mathrm{~mm}$ y resistente al sol (Walsh, 1988). Una va cubriendo una excavación circular, la otra hace las veces de domo. La membrana superior debe tener un sello de agua o equivalente en su conexión con la membrana que recubre la excavación. El afluente entra por un lado y el efluente descarga por el lado opuesto, mediante una tubería de plástico superior a $10 \mathrm{~cm}$ en diámetro. El gas se recoge desde la parte superior del domo (que se infla debido a la presión del gas). Esta instalación con forma de lenteja es apta para tratamiento de aguas servidas, pero más compleja de instalar en una aldea campesina.

El sistema que mejor se adapta a las necesidades de familias campesinas es el biodigestor tubular de geoplástico (Preston, 2005). Su tecnología es simple y económica con una fácil instalación. Generalmente consiste en una manga de polietileno de $1,2 \mathrm{~m}$ de diámetro por $6 \mathrm{~m}$ de largo. Se puede emplear en sitios planos o de superficie complicada, tanto en sectores urbanos o rurales. Este método está al alcance de más personas, como ejemplo se cita a Vietnam donde existen unas 30.000 instalaciones. No se requiere de subsidios porque los materiales son económicos y están disponibles en casi todo el mundo. Debe incorporarse un depósito de gas cerca de la cocina porque la presión del biodigestor es baja y hay pérdidas entre este y el punto de consumo. Este depósito también es de manga de polietileno doble, se puede incrementar su presión mediante una faja ceñida o añadiendo carga sobre la parte superior. El precio del polietileno empleado bordea los US\$ $10 \mathrm{y}$ tarda unas 4 horas en ser recambiado (en caso de ruptura de la manga). Se recomienda montar la manga cerca del corral de los animales. Por medio de un canal impermeabilizado escurrir con agua los desechos, mediante la gravedad y una pendiente de unos $5^{\circ}$ introducir el afluente a la manga con una tubería de PVC diámetro mínimo $150 \mathrm{~mm}$ y $1 \mathrm{~m}$ de longitud. Se puede hacer una estimación del volumen del biodigestor calculando a partir que: 10 cerdos de engorda producen un volumen líquido de $4 \mathrm{~m}^{3}$, siendo esta cifra el $80 \%$ de la capacidad total, lo que significa una manga efectiva de $10 \mathrm{~m}$ de longitud, pero debe añadirse $75 \mathrm{~cm}$ por lado para atar y sellar la tubería a la manga, con lo que resultaría un largo de 11,5 m. Por seguridad deben montarse dos mangas, una dentro de la otra, evitando dobleces. Debe hacerse una excavación de mínimas dimensiones: Ancho en el borde superior $1 \mathrm{~m}$, ancho en el borde inferior 70 $\mathrm{cm}$, longitud $10 \mathrm{~m}$. La pendiente del suelo debe ser unos $4^{\circ}$ para que el material fluya hacia la descarga. Hay que suavizar la zanja eliminando piedras y raíces que puedan romper el polietileno. Para que algunos animales no pisen y destruyan la manga, debe ponerse un muro de adobes para protección, fabricado de la misma tierra que se extrajo de la excavación, con un alejamiento de unos $30 \mathrm{~cm}$ de los bordes de la zanja.

Montaje: la unión de la entrada de la tubería de PVC a la manga se pueden realizar usando bandas de caucho de unos 30 a $50 \mathrm{~mm}$ de ancho provenientes de cámaras de automóvil. Se inserta el tubo a la mitad de su longitud dentro de la manga, luego se amarra la manga doble con la banda estirada, de manera que se traslape la banda en cada vuelta. Se debe empezar desde el polietileno hacia la boca de la tubería. Debe dejarse el otro extremo abierto, sin montar la tubería.

La descarga del gas se hace sobre la parte superior del biodigestor a $1,5 \mathrm{~m}$ de un extremo, mediante un tubo de PVC y una manguera de más de $12,5 \mathrm{~mm}$ de diámetro, mediante un dispositivo que selle cualquier fuga por la perforación de la manga.

Para transportar el biodigestor debe cerrarse un extremo de la tubería y la descarga del gas. Se infla con aire la manga desde el lado abierto, mediante la agitación de la manga con los brazos, de manera que el aire entre en oleadas (al igual que al agitar las sábanas de una cama en el momento de extenderlas). Se ata el extremo abierto de la manga con las bandas de caucho, se traslada a la zanja y se monta la tubería de descarga, en similar forma que se hizo con la tubería de entrada. El paso siguiente es llenar la manga con agua hasta sellar la entrada y la salida.

En la manguera o tubería de descarga del gas se monta una trampa de agua (que además sirve de 
apaga llamas en el caso de propagarse una llama desde la cocina hacia la manga). Se emplea una botella de 2 litros de policarbonato transparente, con la mitad de agua. Se emplea una conexión tipo T y la extensión vertical de la tubería dentro de la botella debe quedar cubierta de agua. El fin de este artilugio es tener una válvula de escape, que se pueda ver desde lejos a fin de mantener el nivel apropiado de agua. Debe estar correctamente sellada para no tener fugas y sostenida firmemente a una estructura de madera o metal. Antes de hacer entrar el estiércol conviene purgar el aire de la manga, de lo contrario será más difícil encender el gas.

El depósito de gas debe tener unos $4 \mathrm{~m}$ de largo, hecho con doble manga de polietileno. Debe estar en altura, cerca de la cocina, pero nunca sobre ella. $\mathrm{Su}$ función es tener disponibilidad de gas.

Es conveniente disponer de un colector de $\mathrm{CO}_{2}$, fabricado de una caja sellada con un laberinto interior y relleno con soda cáustica, para atrapar el $\mathrm{CO}_{2}$ y tener una combustión del metano sin impedimentos. También se recomienda instalar una trampa igualmente sellada, debe contener virutilla de hierro, de la empleada para limpiar sartenes. También puede construirse a partir de una botella de policarbonato transparente para visualizar cuando la virutilla está saturada. Su finalidad es captar el $\mathrm{H}_{2} \mathrm{~S}$ que es tóxico y ataca las válvulas metálicas. Para mejorar la eficiencia es aconsejable conectar la letrina doméstica al biodigestor. El costo del biodigestor es de aproximadamente 40 euros $/ \mathrm{m}^{3}$ (Ferrer, 2005).

\section{Método para generar biogás para instalaciones agrícolas mayores}

Este método está diseñado para emplear los desechos el estiércol producidos en las criaderos de porcinos, lecherías y corrales de engorda. Consiste en la instalación de una laguna en las granjas o criaderos de animales.

Esta laguna realmente es el biodigestor. Sobre el fondo de la excavación circular para la laguna, se instala una geomembrana de polietileno de alta densidad. Esta excavación tiene geometría lenticular la que se asegura y sella alrededor del perímetro del biodigestor. Debe emplearse la geomembrana porque es la más económica opción para evitar fugas de líquidos, no se ve afectada por los procesos de biodegradación del estiércol y por su gran resistencia a la radiación solar ultravioleta.
Encima de la geomembrana del suelo se instala otra similar que hace las veces de cubierta. También debe ser sellada sobre la primera, empleando un anillo con sello de agua. La extracción de semisólidos es segura porque no se rompe el sello de retención del gas.

Los efluentes del proceso de biodigestión se trasladan a otra laguna, que sirve para clarificar los desechos y luego emplearlos para otros fines agrícolas. El biogás obtenido se extrae de la parte superior de la "lenteja" o domo del biodigestor y se aprovecha para generar energía eléctrica (FIRCO, 2007 y Pascual, 2011).

Primeramente hay que limpiar el biogás extrayendo el $\mathrm{CO}_{2}$ y el $\mathrm{H}_{2} \mathrm{~S}$, lo que se hace mediante un sistema de torre de limpieza. Esta consiste en un depósito cilíndrico vertical rellena con pebbles (piedritas). Desde la parte inferior se bombea el gas y desde la superior de descarga a agua a presión por un sistema de regaderas. El metano sale puro por el sector alto y el $\mathrm{CO}_{2}$ con el $\mathrm{H}_{2} \mathrm{~S}$ son disueltos y arrastrados por el agua. Este gas se guarda en un depósito separado, con sus correspondientes válvulas de seguridad y control. Luego se conecta la línea de metano a un motor acoplado a un generador. En México ha dado buen resultado la combinación de un motor inglés Econgas-Perkins de 6 cilindros y un generador WEG de $60 \mathrm{~kW}$, síncrono sin escobillas, adecuado para trabajo continuo o intermitente (factor de potencia 0,$8 ; 1.800 \mathrm{rpm} ; 220-240 \mathrm{~V}$ ). Debe ser un motor de combustión interna de alta eficiencia, con bajo costo de inversión, larga vida útil y poco espacio para su instalación. Todo el equipo debe estar protegido bajo techo y con un panel de control.

Estos motogeneradores pueden entregar energía eléctrica mensual por un monto de 43.200 $\mathrm{kW} / \mathrm{h}(60 \mathrm{~kW}$ x 24 horas x 30 días). Esto significa que para emplear esta capacidad instalada debe tener un suministro constante del metano. Estos motores tienen un consumo promedio de $22 \mathrm{~m}^{3} / \mathrm{h}$. Este dato permite conocer el mínimo volumen donde puede ser empleado este equipo. Si el motor trabaja las 24 horas, se requiere un suministro mínimo de $528 \mathrm{~m}^{3} /$ día de metano o $15.841 \mathrm{~m}^{3} /$ mes. Cualquier proyecto debe superar este límite.

También cabe considerar que se puede mejorar la eficiencia del sistema empleando los gases de escape del motor, así mediante un intercambiador de calor sencillo, calentar agua y trasladar esa 
energía al biodigestor (se acelera el proceso con la temperatura). Otra alternativa es acelerar el secado de los efluentes por medio del mismo sistema.

Se destaca que el Fondo Mundial del Medio Ambiente (GEF) entrega aportes para este tipo de proyectos (FIRCO, 2007).

\section{Estudio de costos aproximado}

El costo del equipo motogenerador fue de US\$13.213,5. Los costos de instalación fueron US\$ 13.470. El costo de mantención del motogenerador es US\$ $150 / \mathrm{mes}$, lo que equivale a un costo anual de US 1.800. Los costos del consumo de energía eléctrica al interior de las unidades productivas sería de $31.500 \mathrm{~kW} / \mathrm{h}$ mensuales. El costo por $\mathrm{kW} / \mathrm{h}$ en promedio sería US\$ 0,054 .

El costo promedio mensual de energía eléctrica sería de US\$ 1.701 (31.500 x 0,054), o un costo anual de US\$ 20.412.

Basándose en los flujos de efectivo, para un período de cinco años, la tasa interna de retorno sería del $62 \%$, a una tasa de actualización del $12 \%$; con un valor presente neto de US\$ 38.340 y una relación-beneficio costo de 2.9. La inversión se recupera en 1,5 años. (Fuente: FIRCO, 2007).

\section{Conclusión}

En la actualidad existe una tecnología sencilla, económica y fácil de instalar para la generación de biogás. Se evita la emisión de gases invernadero y se obtiene una fuente energética de bajo costo tanto para familias campesinas como para instalaciones agrícolas de ganadería. Por otro lado, se reduce el consumo de hidrocarburos que son contaminantes y de un costo superior, así como su traslado a regiones remotas de consumo.

\section{Agradecimientos}

El autor agradece al Proyecto DIEXA 8711-15 de la Universidad de Tarapacá por el financiamiento presentado.

\section{Literatura Citada}

Al Seadi,T.; Rutz, D.; Prassal, H.; Kötter, M.; Finsterwalder, T.; Volk, S.; Janssen, R.

2010. Biogas Handbook. University of Dennmark Esbjerg. Esbjerg, Denmark, $125 \mathrm{p}$.

Denker, $\mathrm{H}$.

1966. Manual de Técnica Agrícola. Omega. Barcelona, España, $1252 \mathrm{p}$.

Guardado, J.

2006. Diseño y Construcción de Plantas de Biogás Sencillas. Ed. Cubasolar. Ciudad de La Habana, Cuba, 66 p.

House, D.

1978. The Compleat biogas handbook. At Home Everywhere, Aurora. Oregon, USA. 403 p.

Ministerio de Energía

2010. Antecedentes sobre la matriz energética en Chile y sus desafíos para el futuro. Cuenta Pública, pp. 1-23. Disponible en: http://www.ministeriodeenergia.cl/minwww/opencms/ Consultado: 31/Mayo/ 2014.
Pascual, A.; Ruiz, B.; Gómez, P.; Flotats, X.; Fernández, B.

2011. Situación y Potencial de Generación de Biogás. Estudio Técnico Plan de Energías Renovables (PER) 2010-2011. IDAE. Madrid, España, 100 p.

Preston, T.

2005. Los biodigestores en los sistemas agrícolas ecológicos. LEISA, Revista de Bioingeniería, 21 (1): 18-22.

Secretaría de Agricultura, Ganadería, Desarrollo Rural, Pesca y Alimentación.

2007. Aprovechamiento del biogás para la generación de energía eléctrica en el sector agropecuario. Claridades Agropecuarias, 168 (8): 3-40.

Varnero, M.T.

2012. Manual de Biogás. MINENERGIA / PNUD / FAO / GEF. Santiago, Chile, 119 p.

Walsh, J.; Roos, C.; Smith, M.; Harper, S.; Wilkins, A. 1988. Handbook of biogas utilization. U.S. Department of Energy and Georgia Institute of Technology. Georgia, Atlanta, U.S.A., 133 p. 
